\title{
Transapical transcatheter aortic valve replacement with a novel transcatheter aortic valve replacement system in high-risk patients with severe aortic valve diseases
}

Liming Zhu, MD, ${ }^{\mathrm{a}}$ Yingqiang Guo, MD, ${ }^{\mathrm{b}}$ Wei Wang, MD, ${ }^{\mathrm{c}}$ Huan Liu, MD, ${ }^{\mathrm{a}}$ Ye Yang, MD, ${ }^{\mathrm{a}}$ Lai Wei, MD, and Chunsheng Wang, MD

\section{ABSTRACT}

Objectives: The clinical experience of a novel transapical transcatheter aortic valve replacement system, the J-Valve (JC Medical Inc, Burlingame, Calif), in high-risk patients with severe aortic valve diseases is limited.

Methods: A total of 107 high-risk patients (mean age, $74.4 \pm 5.2$ years) underwent transcatheter aortic valve replacement with the J-Valve from March 2014 to July 2015, which included 63 patients with aortic stenoses and 44 patients with aortic regurgitation. Echocardiography and contrast-enhanced computed tomography were used to evaluate patients' baseline characteristics and their follow-up conditions.

Results: The J-Valve was successfully implanted in 102 patients (95.3\%). Five patients $(4.7 \%)$ underwent conversion to open surgery. The overall mortality was $4.7 \%(\mathrm{n}=5)$ at both 30 days and 6 months, whereas subgroup mortality was $6.3 \%(n=4)$ in the aortic stenosis group and $2.3 \%(n=1)$ in the aortic regurgitation group. Permanent pacemakers were implanted in 5 patients $(4.7 \%)$. In the aortic stenosis group, paravalvular regurgitation was observed as none or trace in $54.2 \%$ of patients $(n=32)$, mild in $42.4 \%$ of patients $(n=25)$, and moderate in $3.4 \%$ of patients $(n=2)$ postprocedure. The mean aortic gradient decreased from $56.7 \pm 15.2 \mathrm{~mm} \mathrm{Hg}$ to $14.4 \pm 7.8 \mathrm{~mm} \mathrm{Hg}(P<.01)$. The peak aortic valve velocity declined from $4.76 \pm 0.6 \mathrm{~m} / \mathrm{s}$ to $2.45 \pm 0.57 \mathrm{~m} / \mathrm{s}(P<.01)$. In the patients with aortic regurgitation, paravalvular regurgitation was none or trace in $74.4 \%$ $(\mathrm{n}=32)$, mild in $23.3 \%(\mathrm{n}=10)$, and $2.3 \%(\mathrm{n}=1)$ after the procedure. Mean aortic gradient was $7.1 \pm 2.9 \mathrm{~mm} \mathrm{Hg}$.

Conclusions: Transcatheter aortic valve replacement by the J-Valve is an adequate clinical option to treat high-risk patients with severe aortic stenosis or aortic regurgitation. (J Thorac Cardiovasc Surg 2018;155:588-97)

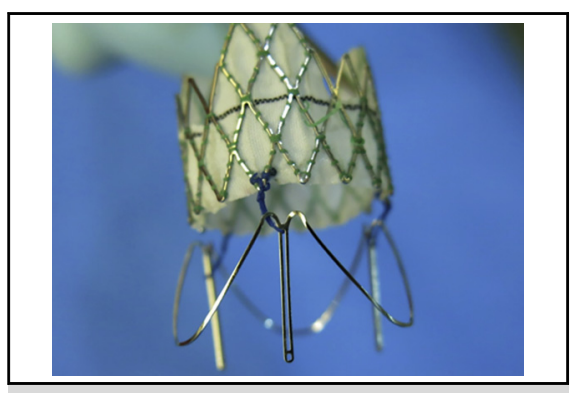

The J-Valve device, with locators loosely connected with the prosthesis, reduces risk and helps positioning.

\section{Central Message}

The new TAVR device, the J-Valve (JC Medical Inc, Burlingame, Calif), designed with locators, is an adequate option in treating patients with $\mathrm{AS}$ or $\mathrm{AR}$

\section{Perspective}

This study introduces the J-Valve (JC Medical Inc, Burlingame, Calif) as a new transapical TAVR system for the treatment of high-risk patients with AS or AR. It is designed with locators to help positioning that can extend its application in patients with AR with promising clinical outcomes.

See Editorial Commentary page 598.

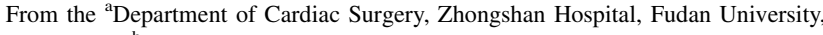
Shanghai; ' Department of Cardiovascular Surgery, West China Hospital, Chengdu, Sichuan; and ${ }^{\mathrm{c}}$ Department of Cardiac Surgery, Fu Wai Cardiovascular Hospital, Beijing, China.

This study is supported, in part, by Grant Number 14DZ1940902 from the Science and Technology Commission of Shanghai Municipality, People's Republic of China. JC Medical, Inc, is the study sponsor, providing the prosthetic valve and part of the patient's follow-up cost with no compensation. All other expenses including but not limited in the TAVR procedure and hospitalization costs were paid by the patients themselves or national healthcare system. All procedure, data collection, and analysis were made or assisted by hospital staffs independently.

Drs Liming Zhu, Yingqiang Guo, and Wei Wang contributed equally to this work.

Received for publication Feb 1, 2017; revisions received Aug 6, 2017; accepted for publication Sept 4, 2017; available ahead of print Oct 6, 2017.

Address for reprints: Chunsheng Wang, MD, and Lai Wei, MD, Department of Cardiac Surgery, Zhongshan Hospital, Fudan University, No. 180 Fenglin Rd, 200032 Shanghai, China (E-mail: zswangcs@126.com and wei.lai@zs-hospital.sh.cn). 0022-5223/\$36.00

Copyright (c) 2017 by The American Association for Thoracic Surgery https://doi.org/10.1016/j.jtcvs.2017.09.015
}

Since the first case of transcatheter aortic valve replacement (TAVR) in 2002, ${ }^{1}$ first-generation systems such as the SAPIEN (Edwards Lifesciences Corp, Irvine, Calif) and CoreValve (Medtronic, Minneapolis, Minn) have been proven to be safe and effective in high-risk patients with aortic stenosis (AS), while further refinements were made to the second-generation SAPIEN 3, Engager (Medtronic), and JenaValve (JenaValve, Munich, Germany). ${ }^{2-5}$ Yet, there

- Scanning this $\mathrm{QR}$ code will take you to a supplemental video for the article.

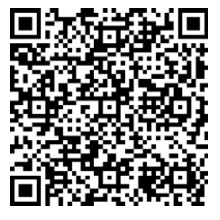




\section{Abbreviations and Acronyms \\ $\mathrm{AR}=$ aortic regurgitation \\ AS $=$ aortic stenosis \\ $\mathrm{CT}=$ computed tomography \\ TAVR $=$ transcatheter aortic valve replacement \\ $\mathrm{TEE}=$ transesophageal echocardiography}

are still challenges inherent within these systems. Difficulties in inaccurate positioning, valve dislocation, paravalvular regurgitation, atrioventricular conduction block, and stroke always await better solutions, ${ }^{6,7}$ and a limited selection of TAVR devices have demonstrated acceptable results in treating pure aortic regurgitation (AR). ${ }^{8,9}$ Design improvements were focused on these challenges, and significant revisions have been made to yield better results. ${ }^{10,11}$

The J-Valve is a newly designed second-generation transapical TAVR system. It consists of a delivery catheter and a self-expanding prosthesis that uses locators to help facilitate positioning during the procedure. We report the initial clinical experience and midterm follow-up of the J-Valve (JC Medical Inc, Burlingame, Calif) device in a series of high-risk patients with severe AS or AR. The China Food and Drug Administration has recently approved the clinical application of the J-Valve in patients with AS and AR. The identity number of the approval is China Food and Drug Administration Certified Number 20173460698.

\section{MATERIALS AND METHODS \\ Patient Evaluation}

Patients were evaluated by a heart team for their eligibility of TAVR. Symptomatic severe AS was defined as New York Heart Association class II or greater, mean gradient greater than $40 \mathrm{~mm} \mathrm{Hg}$, peak aortic valve jet velocity $4.0 \mathrm{~m} / \mathrm{s}$ or greater, and aortic valve area less than $0.8 \mathrm{~mm}^{2}$. Severe AR was defined by standard criteria under echocardiography. ${ }^{12}$ The surgical risk of a patient was assessed through the logistic European System for Cardiac Operative Risk Evaluation. A score greater than 20\% was deemed to be high risk. The inclusion criterion was defined as high-risk patients with severe AS or AR and an annulus diameter within the 19to 27-mm range. Exclusion criteria included bicuspid aortic valve, severe pulmonary hypertension, and sinotubular junction diameter greater than $50 \mathrm{~mm}$. Aortic annulus diameter was measured by transthoracic echocardiography, transesophageal echocardiography (TEE), and contrast-enhanced multislice computed tomography (CT), which was used to assess aortic valve and root morphology. The optimal C-arm angulation for fluoroscopy during the procedure was calculated through CT reconstruction. All patients underwent follow-up examinations by the operating physicians at 30 days and 6 months through clinic visits to the hospital where the implants were performed. Study end points and adverse events were reported according to the Valve Academic Research Consortium-2 consensus document. ${ }^{13}$ The study protocol was approved by the local ethics committee, and all patients or their legal representatives were fully informed about the procedure and signed the written consents.

\section{Valve Design}

The J-Valve system is composed of a bioprosthetic aortic valve and a transapical delivery catheter. The bioprosthetic aortic valve is a porcine valve supported by a self-expanding nitinol structure under different sizes: 21,23 , 25 , and $27 \mathrm{~mm}$. A set of 3 "U"-shaped nitinol hoops were designed around the valve as locators that can sit in 3 aortic sinuses individually to facilitate accurate positioning and fix the native valve. Unlike those found in previous systems, these locators are not unified with the prosthesis but can be fully opened to locate annulus position before valve deployment. The $27 \mathrm{~F}$ transapical delivery catheter (Ausper-AS system, JC Medical Inc) consists of a control system and a carrier component for the prosthesis (Figure 1).

\section{Procedure}

Under general anesthesia, supine patients underwent surgery after Swan-Ganz catheter and pacing wire placement in a surgical hybrid operating room. Before the procedure, the size of the prosthesis and the balloon used for valvuloplasty were selected on the basis of CT measurements and TEE assessment while the principle of $10 \%$ to $20 \%$ oversizing in AR and $10 \%$ in AS was used. The valve was also crimped with locators and mounted onto the delivery system before implantation.

A bolus of $1 \mathrm{mg} / \mathrm{kg}$ dose of heparin was given. The surgical incision was made on the left through the fifth intercostal space to expose the cardiac apex, and 2 purse-string sutures were made to secure the puncture point. A pigtail catheter was placed into the aortic root through the right femoral artery, and an angiography was used to identify optimal C-arm angulation to display 3 aortic sinuses on the same level that was predetermined by CT reconstruction. A guidewire was inserted from the apex passing the aortic valve reaching the descending aorta. The balloon valvuloplasty, if necessary, was performed under rapid ventricular pacing. The delivery catheter was then inserted into the ascending aorta. Locators were released first, and the catheter was pulled back gently to help the 3 locators sit in the aortic sinuses, respectively. By manipulating the deployment handle, the crimped prosthesis would descend from the ascending aorta to the level of locators, which was just in the aortic annulus. Angiography was then performed to verify the position. Repositioning can be achieved by advancing the prosthesis back to the ascending aorta and repeating the process. Finally, the prosthesis was released and deployed with the aid of the locators so that that the native aortic valves were fixed at the middle of the device after self-expansion. No rapid ventricular pacing was needed during deployment. The position and function of the prosthesis were immediately assessed by TEE, and the paravalvular leakage was also evaluated by angiography to determine whether a postimplantation balloon valvuloplasty was necessary. Protamine was given, and a left lateral chest tube was inserted with a standard closure of the intercostal incision. Warfarin was initiated the following day with a target international normalized ratio of 2 to 3 for 3 months. Figure 2 shows the in vitro release process of the J-Valve system, and Figure 3 illustrates the intraoperative angiogram of TAVR procedure by the J-Valve system in 1 patient with AS. Video 1 shows the working pattern of J-Valve and its implantation in a patient with AR.

\section{Statistical Analysis}

Categoric variables are expressed as numbers and percentages. Continuous variables are expressed as mean \pm standard deviation. Changes in continuous variables between baseline and 30-day follow-up were assessed using the paired Student $t$ test. Categoric variables were compared with continuity-corrected chi-square test for dependent samples.

\section{RESULTS}

\section{Baseline Characteristics}

A total of 107 patients (49 female; mean age $74.4 \pm 5.2$ years) underwent TAVR with the J-Valve from March 2014 to July 2015. A total of 63 patients presented 


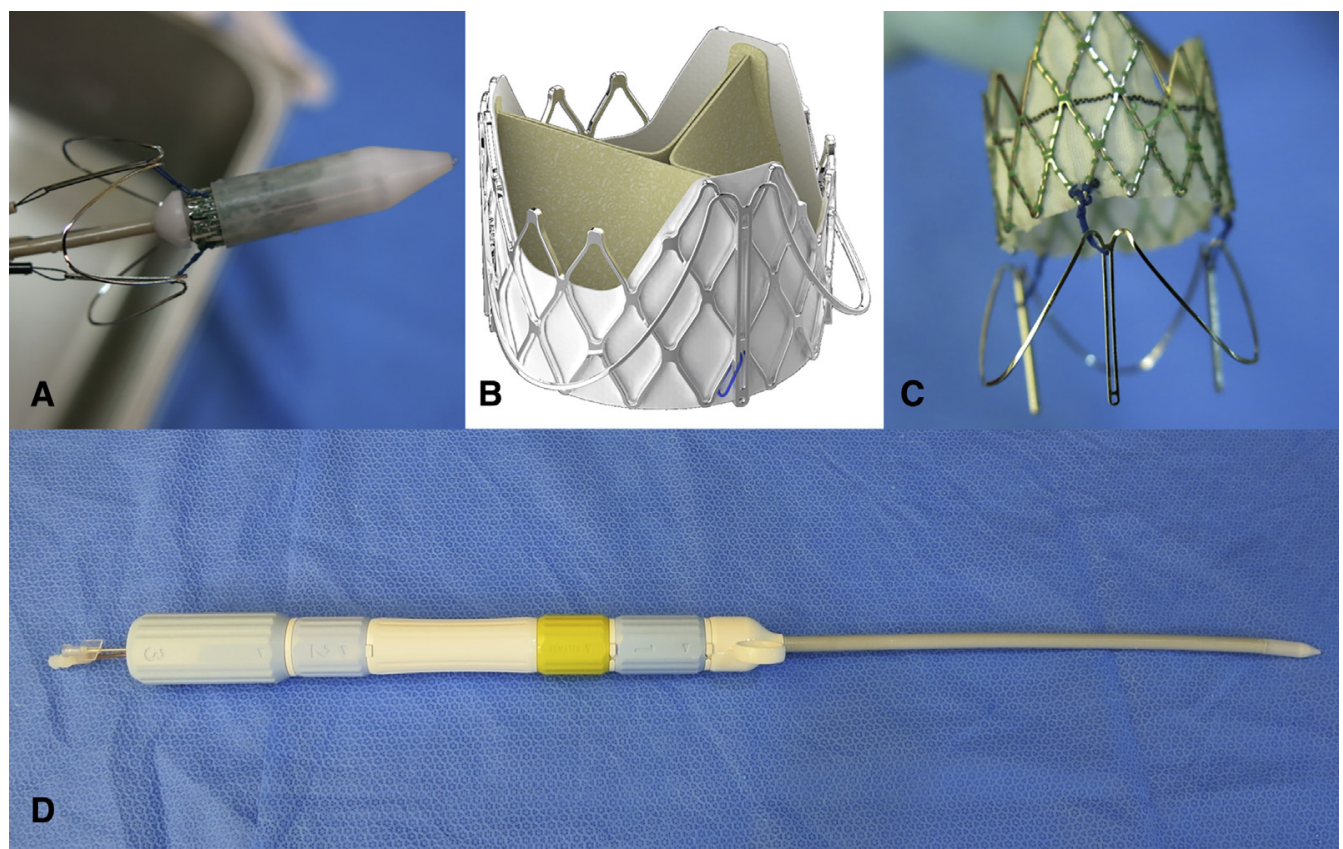

FIGURE 1. The J-Valve (JC Medical Inc, Burlingame, Calif) prosthesis and delivery system. A, Prosthesis was crimped in sheath with locators deployed. B, Prosthesis was combined with locators after release. Courtesy of JC Medical Inc. C, Loose connection between prosthesis and locators by wires. D, 27F Ausper-AS delivery catheter system.

with severe symptomatic AS, and 44 patients sustained pure/dominate severe AR. Mean logistic European System for Cardiac Operative Risk Evaluation was 27.5\% $\pm 8.3 \%$, ranging from $20 \%$ to $63.19 \%$. Society of Thoracic Surgeons score was $9.32 \% \pm 4.15 \%$. The baseline characteristics and aortic valve specifications are summarized in Table 1.

\section{Procedural Results}

Among the 107 patients, 102 (95.3\%) finished TAVR using the J-Valve system and $5(4.7 \%)$ were converted to surgical aortic valve replacement. Of the 5 patients, there were 4 patients with AS and 1 patient with AR. Two patients with AS had a malposition of the prosthesis because of heavy calcification of the native valve that led to moderate to severe paravalvular regurgitation. Another 2 patients with AS were found to have bicuspid aortic valves during surgery that resulted in 1 prosthesis underexpansion and 1 prosthesis dislocation. One patient with AR had a conversion to surgery because of an unsatisfactory prosthetic position under low-quality fluoroscopy and a TEE showing moderate paravalvular regurgitation. These patients were discharged in normal condition.

In the patients with AS, the mean annulus size was $24.2 \pm 2.2 \mathrm{~mm}$ calculated by CT. Among the 63 patients with AS, a $21-\mathrm{mm}$ device was chosen in $7(11.1 \%)$, a $23-\mathrm{mm}$ device was chosen in $22(34.9 \%)$, a $25-\mathrm{mm}$ device was chosen in $25(39.7 \%)$, and a $27-\mathrm{mm}$ device was chosen in $9(14.3 \%)$. The mean aortic gradient was
$14.4 \pm 7.8 \mathrm{~mm} \mathrm{Hg}$ after the procedure, $15.3 \pm 8.6 \mathrm{~mm}$ $\mathrm{Hg}$ at 30-day follow-up, and $16.2 \pm 7.7 \mathrm{~mm} \mathrm{Hg}$ at 6-month follow-up, all of which decreased significantly from the preprocedure gradient of $56.7 \pm 15.2 \mathrm{~mm} \mathrm{Hg}$ $(P<.01)$. The peak aortic valve velocity decreased from $4.76 \pm 0.6 \mathrm{~m} / \mathrm{s}$ to $2.45 \pm 0.57 \mathrm{~m} / \mathrm{s}$ postprocedure, $2.76 \pm 1.1 \mathrm{~m} / \mathrm{s}$ at 30 days, and $2.61 \pm 0.55 \mathrm{~m} / \mathrm{s}$ at 6 months $(P<.01)$. There were 57 patients $(96.6 \%)$ showing mild or less paravalvular regurgitation and 2 patients $(3.4 \%)$ with moderate or more regurgitation after the procedure. At 30 days, all 55 patients who survived had mild or less paravalvular regurgitation and no incident of aggravation found at 6 months. One patient had a prosthesis dislocation of a $23-\mathrm{mm}$ prosthesis implantation, and a $25-\mathrm{mm}$ prosthesis was then anchored properly leaving the former one in the descending aorta with stable hemodynamic condition. Another patient with a $27-\mathrm{mm}$ prosthesis showed moderate prosthetic regurgitation after postoperative balloon valvuloplasty, and then a $25-\mathrm{mm}$ prosthesis was implanted using the valve-in-valve technique that showed mild paravalvular regurgitation and good prosthetic condition.

In the patients with $\mathrm{AR}$, the mean annulus size was $25.4 \pm 1.4 \mathrm{~mm}$ determined by $\mathrm{CT}$, and a $25-\mathrm{mm}$ device was implanted in 13 patients $(29.5 \%)$ and a $27-\mathrm{mm}$ device was implanted in 31 patients $(70.5 \%)$. All patients in the AR group had good valve positions, and 42 patients $(97.7 \%)$ had mild or less paravalvular leakage; 1 patient $(2.3 \%)$ had moderate regurgitation. The mean aortic 


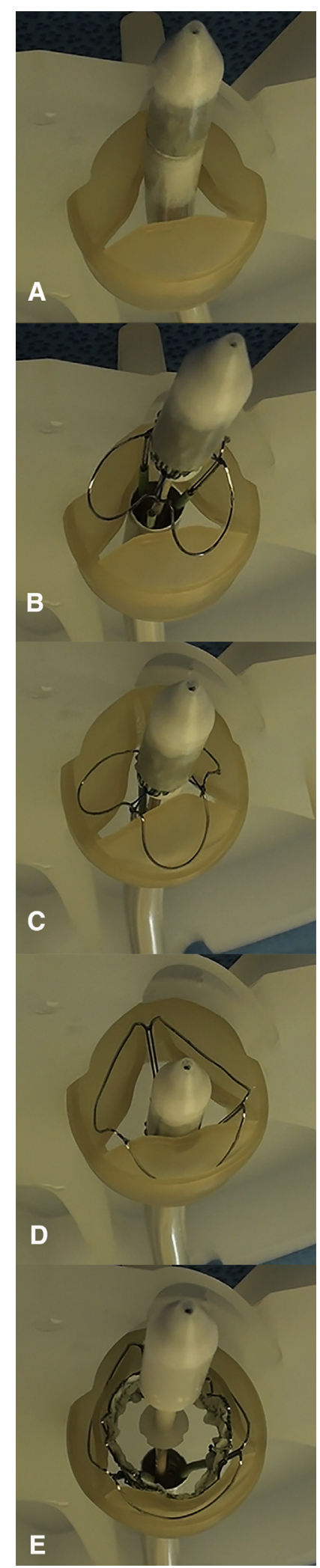

gradient was $7.1 \pm 2.9 \mathrm{~mm} \mathrm{Hg}$, and there was no significant difference from the preprocedure gradient of $10.3 \pm 5.7 \mathrm{~mm}$ $\mathrm{Hg}(P>.05)$. No prosthetic valve dislocation was found in patients with AR, with most patients having no valvular calcification.

There was 1 incidence of a major bleeding event at the apex access site after the release of the prosthetic valve in 1 of the early AS cases, and cardiopulmonary bypass was used. There was no aortic dissection during or after valve implantation. Procedural results are summarized in Table 2. Figure 4 shows the intraoperative angiogram and TEE images of the TAVR procedure by the J-Valve system in a patient with pure AR.

\section{Clinical Outcomes}

The all-cause 30-day and 6-month mortality rate was $4.7 \%(\mathrm{n}=5)$. Of these, 4 patients $(6.3 \%)$ were in the AS group. There was one 87-year-old patient who died of postoperative respiratory dysfunction after a successful implantation of the prosthesis. The patient was extubated on day 3 but reintubated the next day because of respiratory distress with accompanying fever. Echocardiography showed that the mean aortic gradient was $16 \mathrm{~mm} \mathrm{Hg}$ with trivial paravalvular regurgitation and normal left ventricular ejection fraction. Deterioration of respiratory function proceeded, and the patient died on postoperative day 9. Another 80 -year-old patient experienced unsatisfactory prosthetic positioning, and a retrospective examination demonstrated valvular flail between left and right cusps after balloon valvuloplasty in which 1 locator did not sit properly into the aortic sinus because of landing zone calcification. Postprocedural TEE showed mild to moderate paravalvular regurgitation but moderate transvalvular gradient. No intervention was used because a balloon-expanding or a second valve implantation would not improve the outcome. Conversion to surgical aortic valve replacement was unfavorable on the basis of the patient's condition. The patient died on postoperative day 23. The third 79-yearold patient with heavy annulus calcium developed moderate paravalvular leakage after implantation. Echocardiography showed normal prosthesis positioning, and no reintervention or surgical conversion was performed. The patient developed low cardiac output in the intensive care unit and died on postoperative day 6 . The fourth patient was

FIGURE 2. In vitro release process of the J-Valve system. A, Prosthesis was inserted above the aortic annulus. B, Locators were deployed. C, Locators were placed in aortic sinuses respectively. D, Prosthesis descended to the annulus level. E, Prosthesis was released, and native aortic valve was fixed between prosthesis and locators. 


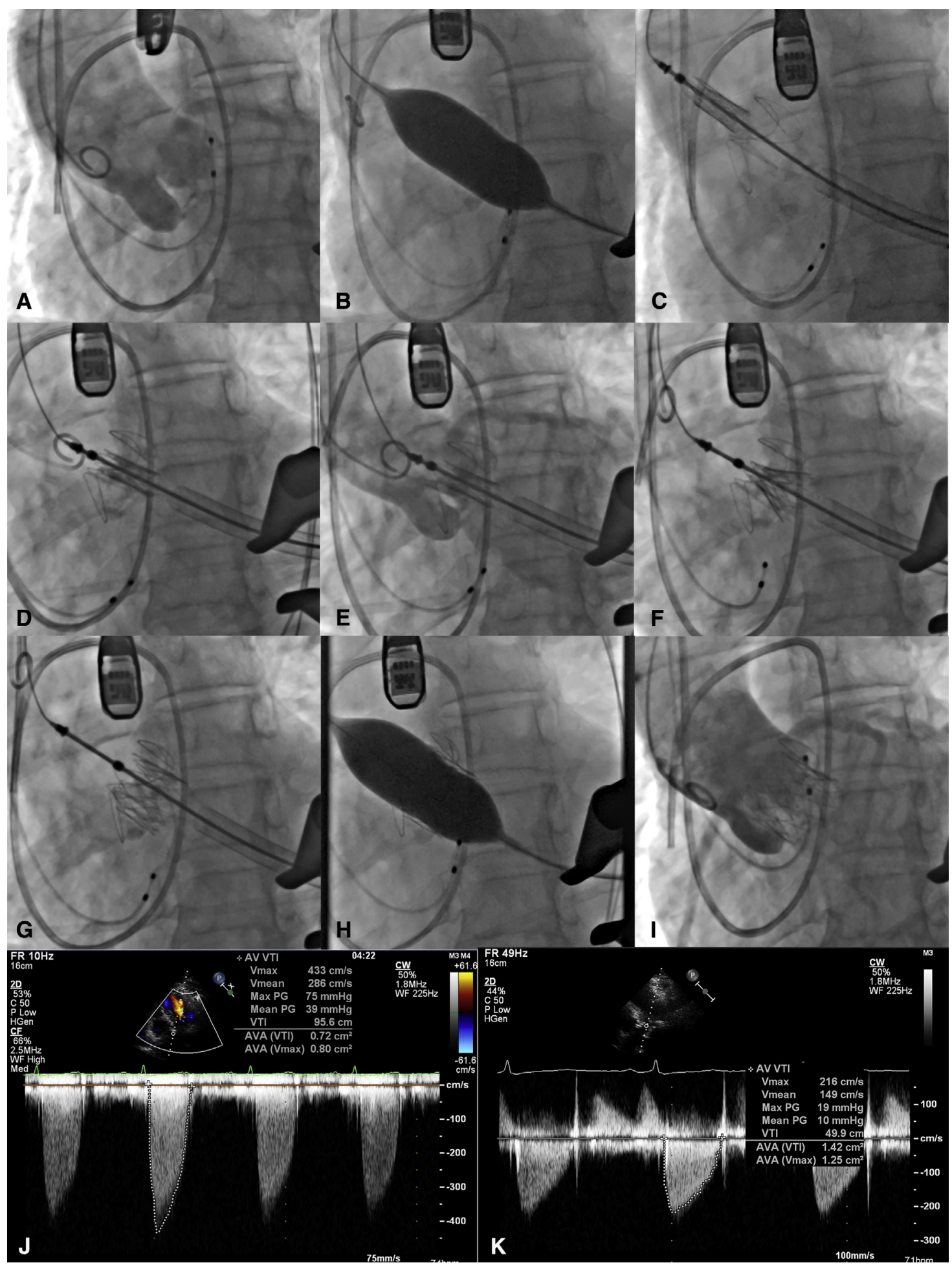

FIGURE 3. Intraoperative angiogram of TAVR procedure by the J-Valve system in a patient with AS. A, Aortic root angiogram to set up optimal C-arm angulation. B, Aortic balloon valvuloplasty to expand the orifice of the aortic valve. C, Prosthesis was inserted above the aortic annulus to the ascending aorta, and locators were deployed. D, Prosthesis descended to the annulus level. E, Aortic root angiogram to verify the position of prosthesis and locators. F, Deployment of prosthesis. G, Successful prosthesis release, but its shape was not optimal on a certain part of the sinus. H, Postoperative balloon dilation was made to reshape the prosthesis system that can lower the incidence of paravalvular leakage. I, Postoperative aortic root angiogram showed proper valve position and trace paravalvular leakage. J, Preoperative TEE image showed severe AS. K, Postprocedural TEE showed significantly decreased pressure gradient across the aortic valve. 


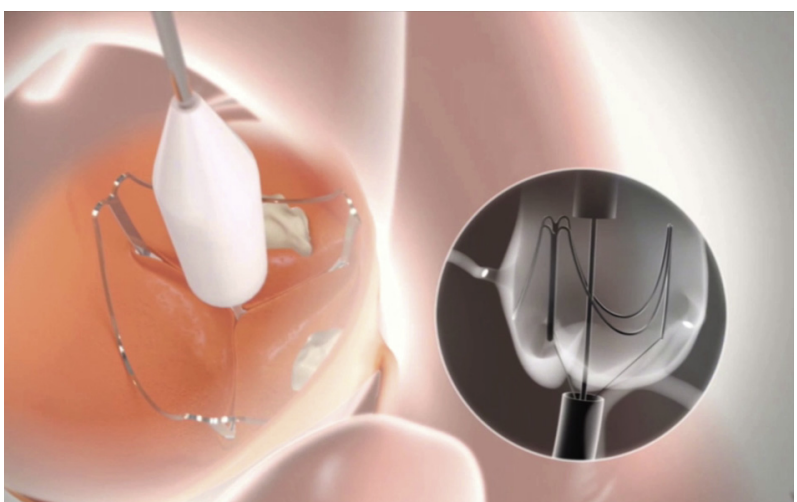

VIDEO 1. The introduction of TAVR by the J-Valve (JC Medical Inc, Burlingame, Calif) system in our center. The video includes an animation demonstration of the working pattern of the J-Valve and a case sharing in which a 79-year-old patient with severe AR underwent TAVR with the J-Valve in a hybrid operation room. Video available at: http://www. jtcvsonline.org/article/S0022-5223(17)31918-9/fulltext.

discharged on postoperative day 7 with the aortic gradient at $7 \mathrm{~mm} \mathrm{Hg}$ and a mild paravalvular leakage, but had a cardiac arrest the next day at home. In regard to other related complications, renal replacement therapy was used in 2 patients $(3.2 \%), 1$ for acute hepatic and renal injury and 1 for postoperational low cardiac output. Both patients followed up well. The overall mean left ventricular ejection fraction improved significantly from $57.6 \% \pm 12.1 \%$ to $63.4 \% \pm 7.7 \%$ at 6 months $(P<.01)$, and there were 3 $(4.8 \%)$ new permanent pacemaker implantations.

In the AR group, 1 patient $(2.3 \%)$ died at follow-up. The 80 -year-old patient with end-stage cardiac function whose ejection fraction was $27 \%$ underwent TAVR as an emergency surgery. The largest $27-\mathrm{mm}$ prosthesis was implanted, and its actual diameter calculated by CT was $29.6 \mathrm{~mm}$. Moderate paravalvular leakage occurred after implantation. Open surgery was not considered because of the overall condition of the patient, and renal replacement therapy was used as a critical treatment. The patient died of heart failure on postoperative day 26. Two patients $(4.5 \%)$ had late conversion to open surgery. One patient with a $27-\mathrm{mm}$ prosthesis implantation showed symptoms of heart failure and increased paravalvular regurgitation to more than moderate on day 6 . The patient underwent surgical aortic valve replacement, and the prosthesis was found positioned on site, but nevertheless, a leakage developed between the prosthesis and the flat oval-shaped annulus. The other patient showed severe AS at the 6-month follow-up. Surgery was performed to find that the prosthesis was steady on annulus with intact leaflets, but the sinuses were filled with pannus that interfered with the movement of leaflets. Both patients followed up well after surgery. For all patients with AR, the mean left ventricular ejection fraction
TABLE 1. Baseline characteristics of patients

\begin{tabular}{|c|c|c|}
\hline Variable & $\begin{array}{c}\text { Aortic } \\
\text { stenosis } \\
(n=63)\end{array}$ & $\begin{array}{c}\text { Aortic } \\
\text { regurgitation } \\
(n=44)\end{array}$ \\
\hline Female & $36(57.1)$ & $13(29.5)$ \\
\hline Age $(y)$ & $74.8 \pm 4.8$ & $73.8 \pm 5.6$ \\
\hline Logistic euroSCORE $(\%)$ & $28.9 \pm 9.6$ & $25.4 \pm 5.3$ \\
\hline STS score $(\%)$ & $9.5 \pm 4.5$ & $9.1 \pm 3.6$ \\
\hline $\operatorname{BMI}\left(\mathrm{kg} / \mathrm{m}^{2}\right)$ & $23.7 \pm 3.8$ & $22.5 \pm 3.1$ \\
\hline \multicolumn{3}{|l|}{ NYHA class } \\
\hline III & $38(60.3)$ & $28(63.6)$ \\
\hline IV & $23(36.5)$ & $15(34.1)$ \\
\hline LVEF (\%) & $57.6 \pm 12.1$ & $56.0 \pm 10.7$ \\
\hline Ejection fraction $<50 \%$ & $13(20.6)$ & $14(31.8)$ \\
\hline Renal impairment (GFR $<60 \mathrm{~mL} / \mathrm{min})$ & $44(69.8)$ & $29(65.9)$ \\
\hline Peripheral vascular disease & $36(57.1)$ & $20(45.4)$ \\
\hline Chronic lung disease & $33(52.4)$ & $26(59.1)$ \\
\hline Previous stroke & $33(52.4)$ & $28(63.6)$ \\
\hline Previous cardiac surgery & $1(1.6)$ & $2(4.5)$ \\
\hline Atrial fibrillation & $11(17.5)$ & $10(22.7)$ \\
\hline Aortic valve area $\left(\mathrm{cm}^{2}\right)$ & $0.67 \pm 0.16$ & $2.6 \pm 0.46$ \\
\hline Mean aortic valve gradient ( $\mathrm{mm} \mathrm{Hg}$ ) & $56.7 \pm 15.2$ & $10.3 \pm 5.7$ \\
\hline Peak aortic valve velocity $(\mathrm{m} / \mathrm{s})$ & $4.76 \pm 0.6$ & $2.1 \pm 0.56$ \\
\hline LVEDD (mm) & $51.4 \pm 7.5$ & $60.6 \pm 8.3$ \\
\hline \multicolumn{3}{|l|}{ Aortic valve regurgitation } \\
\hline None or trace & $14(22.2)$ & $0(0)$ \\
\hline Mild & $26(41.3)$ & $0(0)$ \\
\hline Moderate & $17(27)$ & $11(25)$ \\
\hline Severe & $6(9.5)$ & $33(75)$ \\
\hline \multicolumn{3}{|l|}{ Mitral valve regurgitation } \\
\hline Moderate & $1(1.6)$ & $1(2.3)$ \\
\hline Severe & $2(3.2)$ & $0(0)$ \\
\hline
\end{tabular}

Categoric variables are presented as $\mathrm{n}(\%)$; continuous variables are mean \pm standard deviation. euroSCORE, European System for Cardiac Operative Risk Evaluation; STS, Society of Thoracic Surgeons; BMI, body mass index; NYHA, New York Heart Association; $L V E F$, left ventricular ejection fraction; $G F R$, glomerular filtration rate; $L V E D D$, left ventricular end-diastolic diameter.

improved from $56.0 \% \pm 10.7 \%$ to $59.9 \% \pm 9.6 \%$ at 6 months $(P=.30)$, and 2 patients $(4.5 \%)$ had new permanent pacemaker implantations.

No stroke events were reported at 30 days and 6 months in both AS and AR groups. Clinical outcomes at 6 months are summarized in Table 3.

\section{DISCUSSION}

\section{Locators and Valve Design}

TAVR has evolved into a routine procedure with the development of prosthetic devices to treat high-risk patients with AS and now AR. Studies of off-label treatment of severe pure/dominate AR using the Medtronic CoreValve 
TABLE 2. Procedural results

\begin{tabular}{|c|c|c|}
\hline Variable & $\begin{array}{c}\text { Aortic stenosis } \\
\quad(n=63)\end{array}$ & $\begin{array}{l}\text { Aortic regurgitation } \\
\qquad(\mathrm{n}=\mathbf{4 4})\end{array}$ \\
\hline Implantation of prosthesis & $63(100)$ & $44(100)$ \\
\hline Annulus size by TEE (mm) & $21.9 \pm 1.9$ & $23.7 \pm 2.0$ \\
\hline Annulus size by CT (mm) & $24.2 \pm 2.2$ & $25.4 \pm 1.4$ \\
\hline \multicolumn{3}{|l|}{ Prosthesis size } \\
\hline Mean size $(\mathrm{mm})$ & $24.1 \pm 1.7$ & $26.4 \pm 0.9$ \\
\hline $21 \mathrm{~mm}$ & $7(11.1)$ & $0(0)$ \\
\hline $23 \mathrm{~mm}$ & $22(34.9)$ & $0(0)$ \\
\hline $25 \mathrm{~mm}$ & $25(39.7)$ & $13(29.5)$ \\
\hline $27 \mathrm{~mm}$ & $9(14.3)$ & $31(70.5)$ \\
\hline Conversion to open surgery & $4(6.3)$ & $1(2.3)$ \\
\hline Cardiopulmonary bypass & $5(7.9)$ & $1(2.3)$ \\
\hline Prosthesis dislocation & $2(3.2 \%)$ & $0(0)$ \\
\hline Coronary obstruction & $0(0)$ & $0(0)$ \\
\hline Annulus rupture & $0(0)$ & $0(0)$ \\
\hline Mean aortic gradient $(\mathrm{mm} \mathrm{Hg})$ & $14.4 \pm 7.8$ & $7.1 \pm 2.9$ \\
\hline Peak aortic valve velocity $(\mathrm{m} / \mathrm{s})$ & $2.45 \pm 0.57$ & $1.81 \pm 0.31$ \\
\hline LVEF $(\%)$ & $58.6 \pm 11.0$ & $52.1 \pm 10.0$ \\
\hline \multicolumn{3}{|l|}{ Paravalvular AR } \\
\hline None or trace & $32(54.2)$ & $32(74.4)$ \\
\hline Mild & $25(42.4)$ & $10(23.3)$ \\
\hline Moderate & $2(3.4)$ & $1(2.3)$ \\
\hline Severe & $0(0)$ & $0(0)$ \\
\hline
\end{tabular}

$\overline{\text { Categoric variables are presented as } \mathrm{n}(\%) \text {; continuous variables are mean } \pm \text { standard }}$ deviation. TEE, Transesophageal echocardiography; $C T$, computed tomography; $L V E F$, left ventricular ejection fraction; $A R$, aortic regurgitation.

and Edwards SAPIEN have reported moderate results. ${ }^{9,14}$ Second-generation TAVR devices, such as the JenaValve and Engager, extended their application in patients with AR by using supporting arms that can help locate and fix the prosthesis at the appropriate level in the aortic annulus. ${ }^{10,15}$ The balloon-expandable Engager and the self-expanding JenaValve are equipped with unified locators; thus, the supporting arms would not reach their full expansion before valve deployment. This carries the risk of inaccurate positioning and potential injury of the aortic sinus by the unexpanded tips of the arms. The J-Valve device separates locators from the prosthetic structure using wires to connect them so that its arms can be fully expanded during positioning. This unique structure design may help reduce the risk of injury.

Locators can be used to target aortic annulus with tactile feedback even in patients with pure AR whose leaflets are often absent of fluoroscopically opaque calcification. Furthermore, these locators would fix the native valve to the prosthesis after valve deployment. This provides an axial supporting force to the new bioprosthetic valve system in addition to the radial securing force from the expansion of the prosthesis. Because prosthetic dislocation has been the roadblock that impedes the application of other devices in patients with $\mathrm{AR},{ }^{9}$ this extra-axial supporting force can help reduce the dislocation incidents in AR. As of 6-month follow-up, there have been no reported cases of dislocation in AR cases with the J-Valve system.

\section{Paravalvular Regurgitation}

In some cases, the J-Valve device would demonstrate mild or more paravalvular regurgitation after implantation even if positioned properly, yet after a typical 30-minute expansion process it would self-correct the immediate postsurgical regurgitation without the need for further intervention. There were 6 cases $(9.5 \%)$ of moderate or more severe paravalvular regurgitation in the AS group and 2 cases (4.5\%) in the AR group. After analysis, these cases demonstrated evidence of malpositioning due to heavy leaflets calcification in AS or missed positioning of the locator. The learning curve of the new TAVR procedure may explain part of the outcome. However, procedural protocols were also implemented to reduce the incidence of leakage that include excluding possible stenotic bicuspid aortic valve, sufficient preoperative balloon valvuloplasty, and verification of the locator's position. Other preventive measures included prosthesis oversizing and precise positioning. In terms of oversizing, it is perceived that annular size calculated by CT was more practical in prosthesis size determination than with TEE. This may because annular size calculated by TEE reflected only 1 specific plane of the annulus, and in most cases, it would underestimate the actual size.

In regard to a unique behavior during positioning, normally two thirds of the valve would be positioned above the aortic annulus before release, yet the position of the J-Valve would often be slightly lower than expected even without a backward force from the delivery catheter after a typical release. This may be due to valve release without balloon expansion or rapid cardiac pacing, resulting in direct exertion of the aortic diastolic pressure on the valve that can push it down to the left ventricular outflow tract. Possible outcomes can be atrioventricular block, decreased valvular area, and paravalvular leakage. So far, there have been no complications found related to that phenomenon directly under the J-Valve system. Further investigations would broaden our understanding of the system, and studies involving pacing or not pacing and balloon expanding versus self-expanding should be conducted.

\section{Transapical Approach and Transcatheter Aortic Valve Replacement in Aortic Regurgitation}

The second-generation transapical TAVR devices, the JenaValve, Engager, and Symetis Acurate (Ecublens, Switzerland), have proven their feasibility in patients with AS. ${ }^{16}$ The incidence of complications according to Valve Academic Research Consortium-2 definition in the J-Valve 


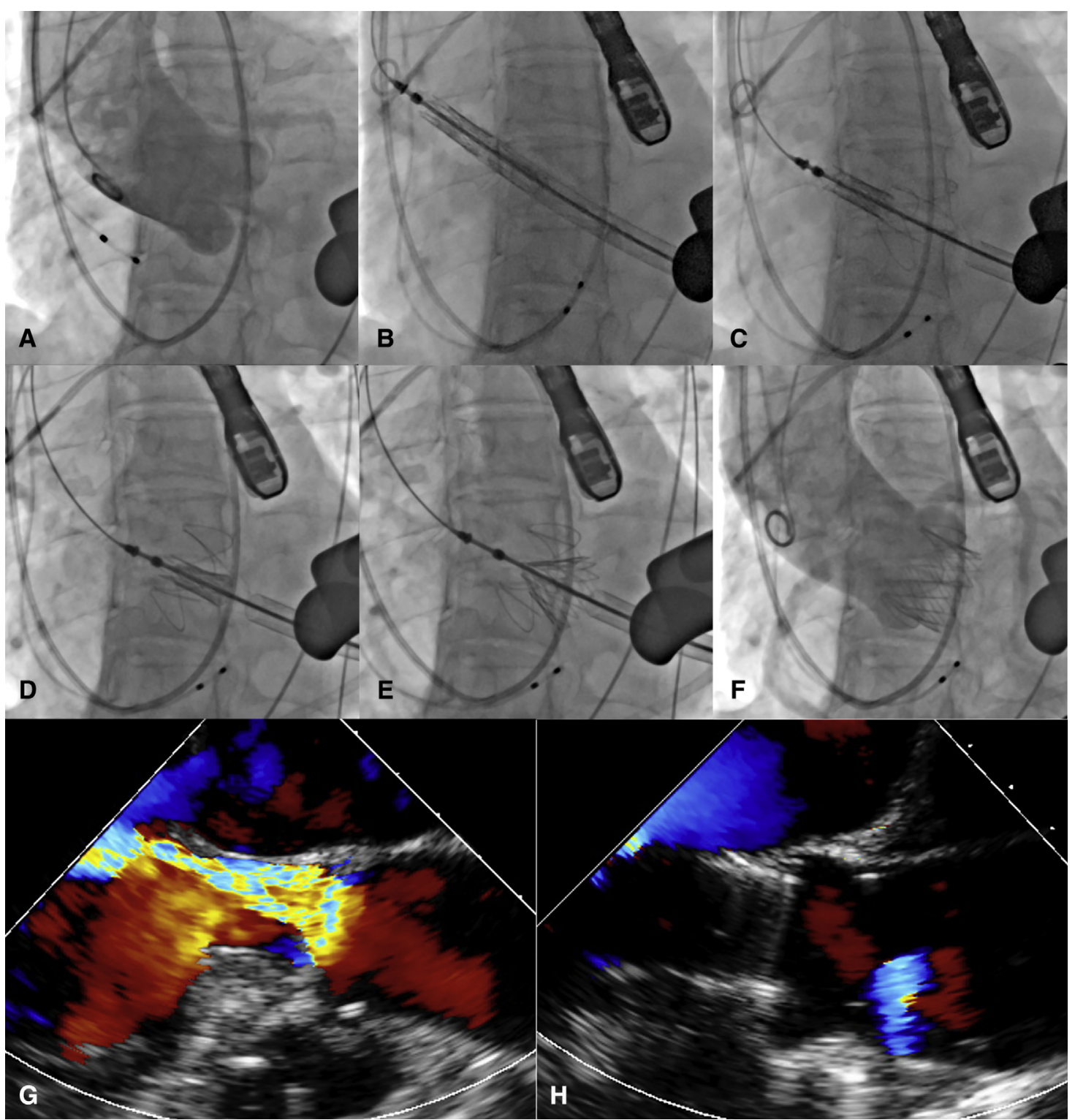

FIGURE 4. Intraoperative angiogram and TEE images of TAVR procedure by the J-Valve system in a patient with pure AR. A, Aortic root angiogram to set up optimal C-arm angulation. B, Prosthesis was inserted above the aortic annulus to the ascending aorta. C, Locators were deployed and sat into the aortic sinuses. D, Prosthesis descended to the annulus level. E, Deployment of the prosthesis. F, Postoperative aortic root angiogram showed proper valve position without paravalvular leakage. G, Preoperative TEE image showed severe aortic regurgitation. H, Postprocedural TEE showed proper prosthetic position without paravalvular leakage.

was similar compared with these devices. There were relatively low rates of major bleeding, access site complication, and permanent pacemaker implantation in the J-Valve study. We reported a pacemaker implantation rate of $4.8 \%$, whereas other transapical devices demonstrated rates of $14 \%$ to $30 \% .{ }^{16}$ It is possible that the 2 -step positioning design of the J-Valve can help prevent the prosthesis from locating too deep into the left ventricular outflow tract that may cause the atrioventricular block. Although our initial experience with the J-Valve demonstrated higher surgical conversion rates, we anticipate declined incidence in the future with the implementation of improved patient screening and procedural standards. Lower paravalvular regurgitation rates were also expected under such circumstances.

Although a similar cardiac mortality rate was reported in patients with AS $(4.8 \%)$, it was relatively lower in patients with AR (2.3\%) compared with the JenaValve $(3.2 \%) .{ }^{17}$ In an era when AR is still not a routine indication for TAVR, the J-Valve and JenaValve showed their feasibility in treating patients with AR with the use of locators and the transapical approach. A transfemoral route 
TABLE 3. Clinical outcomes at 6 months according to Valve Academic Research Consortium-2 ${ }^{13}$

\begin{tabular}{llc}
\hline \multicolumn{1}{c}{ Variable } & $\begin{array}{c}\text { Aortic stenosis } \\
(\mathbf{n}=\mathbf{6 3})\end{array}$ & $\begin{array}{c}\text { Aortic regurgitation } \\
(\mathbf{n}=\mathbf{4 4})\end{array}$ \\
\hline Myocardial infarction & $0(0)$ & $0(0)$ \\
Major stroke & $0(0)$ & $0(0)$ \\
Major bleeding & $1(1.6)$ & $0(0)$ \\
Access site complications & $1(1.6)$ & $0(0)$ \\
\hline Acute kidney injury (stage 3) & $2(3.2)$ & $1(2.3)$ \\
New permanent pacemaker & $3(4.8)$ & $2(4.5)$ \\
\hline Late conversion to surgery & $0(0)$ & $2(4.5)$ \\
All-cause mortality, 30 d & $4(6.3)$ & $1(2.3)$ \\
\hline Cardiac mortality, 30 d & $3(4.8)$ & $1(2.3)$ \\
All-cause mortality, 6 mo & $4(6.3)$ & $1(2.3)$ \\
Cardiac mortality, 6 mo & $3(4.8)$ & $1(2.3)$ \\
\hline
\end{tabular}

Categoric variables are presented as $n(\%)$; continuous variables are mean \pm standard deviation.

shows its advantage with minimal invasion and a shorter learning curve, whereas a transapical method provides an alternative in patients with peripheral artery disease and a calcified aorta. It is also recognized that the guidewire is easier to advance through the antegrade direction rather than the retrograde transfemoral approach with the incidence of cerebrovascular events being relatively lower under transapical method. ${ }^{18}$ In treating AR with the JValve, the transapical approach allows the locators to sit in the sinuses when pulling the catheter from the apex, which is straightforward and cannot be easily achieved through alternative routes.

Our study describes the clinical results in patients with AS that were not reported in previous articles on the J-Valve. ${ }^{19}$ Fewer perioperative complications were observed in patients with AR than in patients with AS. This may result from less calcification in AR, which can lead to better positioning and prosthetic shape after release, which induced a lower incidence of paravalvular regurgitation. No balloon valvuloplasty was necessary for AR, and its easier deployment would result in reduced surgical time and contrast use in comparison with AS.

Currently, the application of TAVR in lower-risk patients is under discussion. The fact that TAVR was first recommended in high-risk rather than low-risk patients with AS was based on the presumption that TAVR was not better than surgical aortic valve replacement in low-risk cases. This was mostly because it preserves the calcified native valve rather than excising it. In AR cases, the preservation of the native valve during TAVR was less influential than in AS in regard to paravalvular leakage and clinical outcomes. Some technique challenges of prior-generation devices, which included dislocation without securing areas and the absence of landmarks in AR, limited its use in these patients. The next-generation transapical systems, especially the J-Valve, resolved these problems by using a set of fully opened locators to help secure the prosthesis to the native valve and provide the promise of improved outcomes. Moreover, this may imply that the use of second-generation devices in TAVR is feasible in lower-risk patients and possibly in patients with AR first.

\section{CONCLUSIONS}

The transapical TAVR J-Valve system proves its feasibility in treating high-risk patients with severe aortic valve disease through the initial multicenter clinical experience. Its design uniquely features locators that improve positional accuracy and prosthetic fixation, resulting in promising results in AS and especially AR. Larger and longer-term follow-up studies are warranted to confirm its prosthetic durability and patient safety.

\section{Conflict of Interest Statement}

Authors have nothing to disclose with regard to commercial support.

\section{References}

1. Cribier A, Eltchaninoff H, Bash A, Borenstein N, Tron C, Bauer F, et al. Percutaneous transcatheter implantation of an aortic valve prosthesis for calcific aortic stenosis: first human case description. Circulation. 2002;106: 3006-8.

2. Walther T, Thielmann M, Kempfert J, Schroefel H, Wimmer-Greinecker G, Treede H, et al. One-year multicentre outcomes of transapical aortic valve implantation using the SAPIEN XT valve: the PREVAIL transapical study. Eur J Cardiothorac Surg. 2013;43:986-92.

3. Reuthebuch O, Inderbitzin DT, Ruter F, Jeger R, Kaiser C, Buser P, et al. Single-center experience and short-term outcome with the JenaValve: a second-generation transapical transcatheter aortic valve implantation device. Innovations (Phila). 2014;9:368-74.

4. Sundermann SH, Holzhey D, Bleiziffer S, Treede H, Jacobs S, Falk V. Secondgeneration transapical valves: the Medtronic Engager system. Multimed Man Cardiothorac Surg. 2014;2014:mmu001.

5. Schymik G, Lefevre T, Bartorelli AL, Rubino P, Treede H, Walther T, et al. European experience with the second-generation Edwards SAPIEN XT transcatheter heart valve in patients with severe aortic stenosis: 1-year outcomes from the SOURCE XT Registry. JACC Cardiovasc Interv. 2015; 8:657-69.

6. Tamburino C, Capodanno D, Ramondo A, Petronio AS, Ettori F, Santoro G, et al. Incidence and predictors of early and late mortality after transcatheter aortic valve implantation in 663 patients with severe aortic stenosis. Circulation. 2011;123:299-308.

7. Linke A, Wenaweser P, Gerckens U, Tamburino C, Bosmans J, Bleiziffer S, et al. Treatment of aortic stenosis with a self-expanding transcatheter valve: the International Multi-centre ADVANCE Study. Eur Heart J. 2014;35:2672-84.

8. Kodali SK, Williams MR, Smith CR, Svensson LG, Webb JG, Makkar RR, et al. Two-year outcomes after transcatheter or surgical aortic-valve replacement. $N$ Engl J Med. 2012;366:1686-95.

9. Roy DA, Schaefer U, Guetta V, Hildick-Smith D, Mollmann H, Dumonteil N, et al. Transcatheter aortic valve implantation for pure severe native aortic valve regurgitation. J Am Coll Cardiol. 2013;61:1577-84.

10. Kempfert J, Rastan AJ, Mohr FW, Walther T. A new self-expanding transcatheter aortic valve for transapical implantation - first in man implantation of the JenaValve. Eur J Cardiothorac Surg. 2011;40:761-3.

11. Sundermann SH, Grunenfelder J, Corti R, Rastan AJ, Linke A, Lange R, et al. Feasibility of the Engager ${ }^{\mathrm{TM}}$ aortic transcatheter valve system using a flexible over-the-wire design. Eur J Cardiothoracic Surg. 2012;42:E48-52. 
12. Zoghbi WA, Enriquez-Sarano M, Foster E, Grayburn PA, Kraft CD, Levine RA, et al. Recommendations for evaluation of the severity of native valvular regurgitation with two-dimensional and Doppler echocardiography. J Am Soc Echocardiogr. 2003; 16:777-802

13. Kappetein AP, Head SJ, Genereux P, Piazza N, van Mieghem NM, Blackstone EH, et al. Updated standardized endpoint definitions for transcatheter aortic valve implantation: the Valve Academic Research Consortium-2 consensus document. J Thorac Cardiovasc Surg. 2013;145:6-23.

14. D'Ancona G, Pasic M, Buz S, Drews T, Dreysse S, Hetzer R, et al. TAVI for pure aortic valve insufficiency in a patient with a left ventricular assist device. Ann Thorac Surg. 2012;93:e89-91.

15. Kiefer P, Seeburger J, Mohr FW, Holzhey DM. Transcatheter aortic valve replacement for isolated aortic valve insufficiency: experience with the Engager valve. J Thorac Cardiovasc Surg. 2014;147:e37-38.

16. Seiffert M, Conradi L, Kloth B, Koschyk D, Schirmer J, Schnabel RB, et al. Single-centre experience with next-generation devices for transapical aortic valve implantation. Eur J Cardiothorac Surg. 2015;47:39-45.
17. Seiffert M, Bader R, Kappert U, Rastan A, Krapf S, Bleiziffer S, et al. Initia German experience with transapical implantation of a second-generation transcatheter heart valve for the treatment of aortic regurgitation. JACC Cardiovasc Interv. 2014;7:1168-74.

18. Unbehaun A, Pasic M, Drews T, Penkalla A, Dreysse S, Klein C, et al. Transapical aortic valve implantation: predictors of survival up to 5 years in 730 patients. An update. Eur J Cardiothorac Surg. 2015;47: 281-90.

19. Zhu D, Chen Y, Guo Y, Hu J, Zhang J, Wei X, et al. Transapical transcatheter aortic valve implantation using a new second-generation TAVI system - J-Valve for high-risk patients with aortic valve diseases: initial results with 90-day follow-up. Int J Cardiol. 2015;199:155-62.

Key Words: transcatheter aortic valve replacement, aortic stenosis, aortic regurgitation, second generation transcatheter aortic valve replacement, J-Valve

Readers who found these articles interesting may also like to read the following papers found in recent and future issues of our sister publications, Seminars in Thoracic and Cardiovascular Surgery and Operative Techniques in Thoracic and Cardiovascular Surgery!

Acquired: Aortic Valve: Transcatheter

NEWS AND VIEWS: TAVR vs SAVR: Rising Expectations and Changing Indications for Surgery in Response to PARTNER II Cristiano Spadaccio. Semin Thoracic Surg 2017: 8-11.

ORIGINAL SUBMISSION: Complications after Self-Expanding Transcatheter or Surgical Aortic Valve Replacement John V. Conte. Semin Thoracic Surg 2017: In press. 